\title{
Keynes' Analytical System as an Econometric Tool: Examining Macroeconomic Trends in the U.S. from 1950s to 1980 s
}

\author{
Manuel A. R. Da Fonseca \\ Faculty of Business Administration and Accounting, Federal University of Rio de Janeiro (UFRJ), Rio de Janeiro, Brazil \\ Email: mfonseca@facc.ufrj.br
}

How to cite this paper: Da Fonseca, M.A.R. (2018) Keynes' Analytical System as an Econometric Tool: Examining Macroeconomic Trends in the U.S. from 1950s to 1980s. Theoretical Economics Letters, 8, 1721-1739.

https://doi.org/10.4236/tel.2018.810112

Received: March 27, 2018

Accepted: June 16, 2018

Published: June 19, 2018

Copyright $\odot 2018$ by author and Scientific Research Publishing Inc. This work is licensed under the Creative Commons Attribution International License (CC BY 4.0).

http://creativecommons.org/licenses/by/4.0/

\begin{abstract}
The initial goal of this paper is to develop the standard Keynes' analytical system into a dynamic macro-econometric model, which is then applied to the analysis of macroeconomic indicators for the U.S. from 1950s to 1980s-a period marked by strong volatility of inflation, exchange rates and commodity prices. Based on the results obtained and, in particular, on the model's structure and exogenous variables, it is possible to single out the main factors that explain the macro-trends observed in the American economy. Further, a second and more important goal is to evaluate if a simple macro-dynamic model can be a relevant tool in empirical analysis of macroeconomic developments. The results obtained indicate that, although the elements of the Keynesian system are most often used in a purely theoretical perspective, a macro-econometric model based on those elements can be successfully used in reproducing overall macroeconomic variables in a certain period-and the determinants of those macro-trends can be traced to the model's exogenous variables.
\end{abstract}

\section{Keywords}

Macro-Econometric Modeling, Quantitative Macroeconomic Analysis, Estimation of Structural Models, Solution of Nonlinear Equations

\section{Introduction}

One important consequence of the ways "mainstream macroeconomics"-the meaning of this expression, though, is not free from controversy-has evolved in the last few decades is that models devised to understand and analyze the behavior of the overall economy and to make relevant conclusions about economic 
policies have become ever bigger and more complex. As a justification for this statement, one can bring attention to the predominance of large scale DSGE (Dynamic Stochastic General Equilibrium) models, as well as of VAR (Vector Auto-Regression) models. Nevertheless, a problem that many economists and professionals perceive in these models is that they are not very successful in predicting future developments in macroeconomic aggregates, so that their practical use has been increasingly reduced-especially in financial markets' applications, where decisions have outright implications in terms of making or losing money ${ }^{1}$.

If the models most often used by policymakers are not successful in accounting for future events, then it is very unlikely that they may be useful in the process of comprehending past economic and financial trends. Yet, in their origins, macro-econometric models were built with a distinctive perspective for empirical analysis. In the 1940s, Lawrence R. Klein, one of the pioneers in the field of structural macro-modeling, developed a six-equation dynamic macro-model based on Kalecky's analytical system, which became known as Klein Model I [1] $]^{2}$. For this early model, data series were constructed with annual data for the US from 1920 to $1941-$ a period that includes the most dramatic economic and financial events of the last century. As can be apprehended from Figure 1 and Figure 2, this simple dynamic macro-model is successful in capturing the acute swings that were observed in both GNP and aggregate investment.

If a model reproduces reasonably well the pattern of real macroeconomic variables, and given that the model's solutions derive from its exogenous variables and dynamic properties, then it seems appropriate to conclude that the analysis of the model's structure should contribute to the understanding of the period being examined. In the case of Klein's Model I, there are four exogenous variables: government consumption and taxes, total wages of public workers, and a trend variable $(1931=0)$. Besides, some endogenous variables are included with time lags, contributing to the model's dynamic behavior. One disadvantage of Kalecky's business cycle theory, which is also present in Klein's econometric model, is that price changes are not taken into consideration-the system includes only variables in constant values.

Following the footsteps of Klein Model I, this paper's initial goal is to develop a structural macro-econometric model based on Keynes' analytical system with barely a few simple equations, and evaluate its performance in reproducing major macroeconomic trends in a significant period in American economic history. Further, given that the model's equations reproduce, to a very reasonable degree, the macro trends of the period examined, the system of equations is used to gather information on the determinants of those trends.

\footnotetext{
1"The [financial] crisis showed that the standard macroeconomic models used by central bankers and other policymakers, which go by the catchy name of 'dynamic stochastic general equilibrium' (DSGE) models, neither represent the financial system accurately nor allow for the booms and busts observed in the real world." The Economist, Jan $19^{\text {th }} 2013$ edition.

${ }^{2}$ Klein used as reference the business cycle theory elaborated in [2].
} 


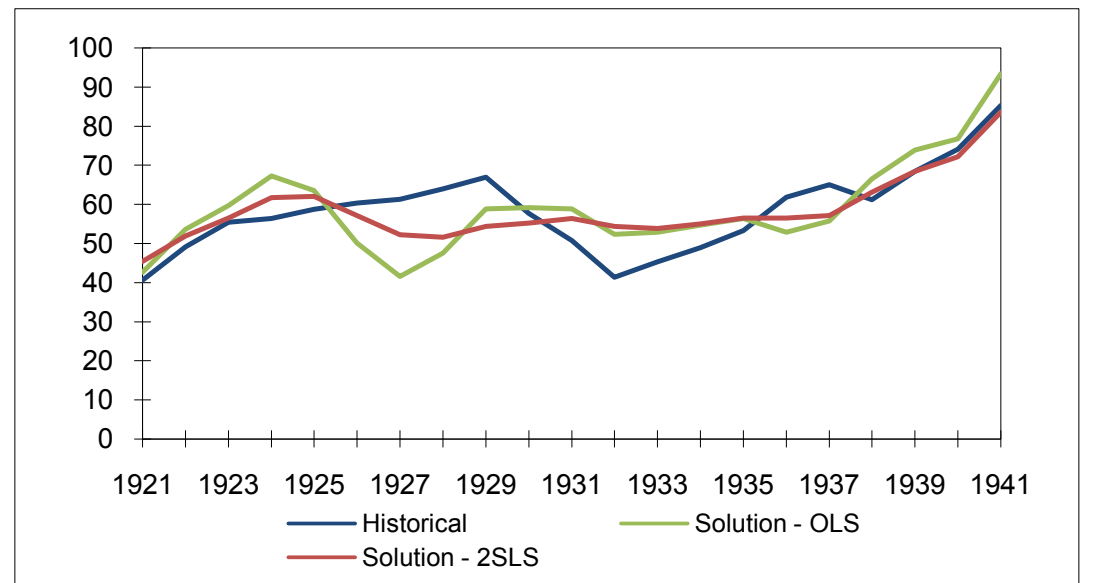

Figure 1. Disposable income in the US: 1921-1941. \$ Billions in constant values of 1934. Note. Solutions from Klein I Model: OLS-parameters estimated by ordinary least squares; 2SLS-parameters estimated by two stage least squares. Source: [1] and solutions obtained by the author.

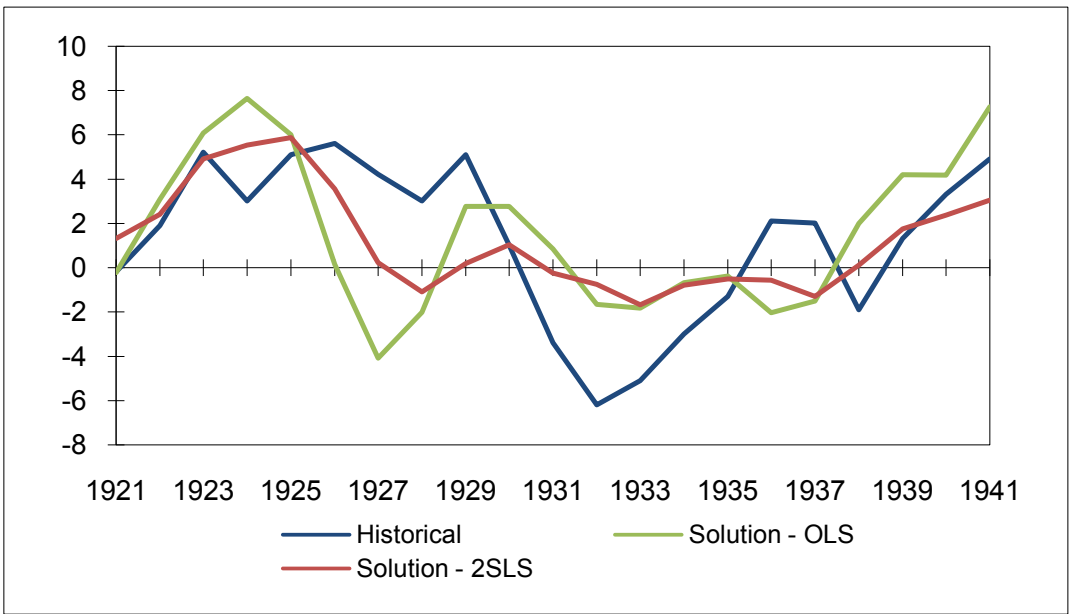

Figure 2. Net aggregate investment in the US: 1921-1941. \$ Billions in constant values of 1934. Note: Aggregate investment less capital depreciation. Source: [1] and solutions obtained by the author.

The main contribution of this paper is, therefore, to put the so-called "complete Keynesian system" [3] in a somewhat different-that is, more applied-perspective. On the other hand, the focus here is relatively narrow, given that more modern contributions in the macro-econometric field are not taken into consideration. Yet, the paper contains brief reviews of estimation methods most often used in econometric models based on simultaneous equations, and the numerical methods required for the solution of nonlinear systems.

In the process of developing and applying the macro model, the Keynesian analytical system is reviewed (Section 2). In Section 3, a few stylized facts for the period examined are presented. Econometric methods used for parameter estimation of structural models are briefly discussed in the following Section, and the estimates for the macro-econometric model are provided. Also in Section 4, 
mathematical methods for the solution of nonlinear systems of equations are summed up-additional concepts on estimation and solution procedures are presented in Appendix 1. In Section 5, the nature of the solutions that were obtained and the results that may be drawn concerning the determinants of the macro-trends are discussed.

\subsection{A Brief Literature Review}

Essentially, macro-econometric models are quantitative tools that can be applied to the analysis and evaluation of economic policies. In a sense, these tools are a natural unfolding of macroeconomic theories-combined with data series, estimation procedures, and numerical methods. From a historical perspective, macro-econometric modelling initiates in the 1940s, and from that period up to the 1960s, there was a mutually beneficial relationship between macro-econometric modelling and macroeconomics per se [4]. The more prominent researchers in the earlier period were J. Tinbergen, L. Klein, and A. Goldberger. Besides the Klein Model I, a groundbreaking contribution, introduced in the 1950s, was the Klein-Goldberger Model [5].

From the 1960s to 1980s, many well-known Econometrics textbooks contained thorough material on structural macro-dynamic models. Good examples are [6] [7] and [8]. More recently, [9] includes a fairly detailed analysis of Klein Model I. A brief and interesting text that applies the developments in this field to macroeconomic planning is [10]. A well-researched paper that examines the relevant contributions up to the 1980s is [11], and a more comprehensive work is [12].

\section{A Simple Model That Transformed Our Understanding of Market Economies-and an Econometric Counterpart}

From the involved and non-mathematical exposition in Keynes' General Theory, published in 1936, one can deduce a fairly simple and straightforward model with equations representing three overall markets: for goods, money and labor. The model's equations are specified below ${ }^{3}$ :

1) Equilibrium output and aggregate production function

$$
\begin{gathered}
Y=C+I+G+(E X-I M) \\
Y=f(L) ; f^{\prime}>0 ; f^{\prime \prime}<0
\end{gathered}
$$

2) Effective demand

$$
\begin{gathered}
C=C(Y-T) ; C^{\prime}>0 \\
I=I(r) ; I^{\prime}<0
\end{gathered}
$$

3) Nominal values

$$
M=M(Y, r) P ; M_{Y}>0 ; M_{r}<0
$$

${ }^{3}$ Although virtually any macroeconomic textbook expands on the topics in this Section, the reference used here is [3]. 


$$
w=\left[\frac{d}{d L} f\right] P
$$

This system of equations is a staple tool in the Macroeconomics field and scarcely needs any further explanation. To a large extent, the contents of any Macroeconomics textbook are related to the concepts and analyses arising from these six equations. In especial, the combination of Equations (1), (3), (4), and (5) produces the standard IS-LM analysis of output and interest rate equilibrium. On the other hand, Equations (2) and (6) are usually dealt with independently of the rest of the system and, therefore, the price level and the labor force employed are often treated in textbook analyses as exogenous elements.

In order to explore some of the economic rationality in this model-that is, causal relations that will indeed be applied in Section 5 below-, we can consider, for example, what would happen in a country where money stock $(M)$ is allowed to increase. An initial effect would be a reduction of $r$, determined by Equation (5). Then, given Equation (4), aggregate investment ( $I$ ) would rise, leading to an increment in $Y$ (Equation (1)). This would cause an increase in $C$ and further increments in $Y$ through the multiplier effect. On the other hand, Equation (2) shows that a larger output depends upon a greater use of labor. However, from the standpoint of firms' profit maximization, a necessary condition for an increase in employment is that the cost of labor should be reduced, in order to compensate for the lower marginal productivity of labor (Equation (6)). This means that larger output and employment depend upon an increment of $P$, so that the real wage rate is reduced (workers behave as if they suffered from monetary illusion, worrying only about the nominal wage rate $w$, at least in the short run). Thus the ultimate effects of an increase of $M$ are increments in $Y, C, I, L$, and $P$, accompanied by a decrease of $r$. As will be seen in Section 5 , this simple analysis is very much in agreement with the macro-trends in the American economy in the period examined, especially in the 1970s and 1980s-that is, consistent growth of GDP and investment that was accompanied by strong money supply, inflation and stagnating average real wage.

Alternatively we can explore the consequences, derived from this six-equation system, of an increment in $G$. An initial effect, given Equation (1), would be a rise of $Y$. Moreover, if $M$ is held fixed, Equation (5) indicates that $r$ should increase, leading to a reduction of $I$ (Equation (4)). These opposing forces compensate each other, leaving $Y$ relatively unchanged-the so-called crowding out effect of higher government spending. However, if $M$ is allowed to increase in order to accommodate the demand pressures set off by an enlarged government spending, then the final results are very much like those derived in the previous paragraph-in the case of the macro-trends in the US, there was consistent growth of Government consumption from 1950s to 1970s.

\section{Macro-Econometric Equations}

In the sequence, a structural macro-econometric model based on Keynes' 
six-equation system is developed - a model that includes variables in both real and nominal values ${ }^{4}$. To start, Equation (2) can be used in one of the other equations so that it can be eliminated-which makes sense given that the empirical development of an aggregate production function is a very challenging endeavor to pursue. Introducing a relation for total employment, $L=f^{-1}(Y)$, and substituting in Equation (6), we get:

$$
w=g(Y) P
$$

Further, for the Keynesian system, one can introduce econometric equations that can be estimated using standard methods-that is, equations that are linear in the parameters. These econometric equations, however, are nonlinear in the endogenous variables - which means that one must use mathematical methods designed to solve nonlinear systems of equations. The most distinctive functional change in relation to the Keynesian system appears in the equation for aggregate investment, where change of GNP is included as a regressor.

1) Econometric equations

$$
\begin{gathered}
Y=C+I+G+(E X-I M) \\
C=\alpha_{0}+\alpha_{1}(Y-T)+\varepsilon_{C} \\
I=\beta_{0}+\beta_{1} r+\beta_{2} \Delta Y+\beta_{3} Y_{-1}+\varepsilon_{I} \\
\frac{M}{P}=\gamma_{0}+\gamma_{1} r+\gamma_{2} Y+\varepsilon_{M} \rightarrow r=\left(\frac{M}{P}-\gamma_{0}-\gamma_{2} Y-\varepsilon_{M}\right) \frac{1}{\gamma_{1}} \\
\ln \left(\frac{w}{P}\right)=\zeta_{0}+\zeta_{1} \ln Y+\varepsilon_{w}
\end{gathered}
$$

2) Variables in the model

a) Endogenous variables: $Y$ : Aggregate income and product, in real values; $C$ : Private consumption, in real values; $I$ : Aggregate investment, in real values; $r$. Interest rate, in real terms; $P$. Average price level.

b) Exogenous variables: $G$ : Government spending, in real values; $E X-I M$ : Trade balance in national currency, real values; $T$ : Taxes, real values; $M$ : Money stock, current values; $w$. Average wage rate, current values.

Equation (4a) includes an endogenous variable with a one period delay and, consequently, this set of equations is a dynamic system-technically, a system of difference equations $s^{5}$. Therefore, this is a structural nonlinear dynamic macro-econometric model. But the fundamental question remains: Is it possible that such a simple system can be of value in analyses of the real world and, especially, in analyses of historical periods marked by major economic and financial changes? Before we can try to answer, the equations must be estimated and solved-these developments are pursued in Section 4. In the next Section, an ${ }^{4}$ This part is based on [13] and [14].

${ }^{5}$ Equation (4a), which shapes the dynamics of the model, plays a unique role in this system-it is actually an example of the "art" of specifying econometric equations. If the model's dynamics works appropriately, it should reproduce with some success the time path of the real macroeconomic variables. 
overview of the period from 1950s to 1980s is presented.

\section{Stylized View of Economic and Financial Trends from the 1950s to 1980s: A perspective Centered on the US Economy}

The main macroeconomic trends in the decades following the end of the Second World War reflected some major regional conflicts-Korean War (1950-3), Vietnam War (1955-75), and the Arab-Israeli War of 1973-, and their effects on price movements of strategic commodities, especially oil. Moreover, the initial period was marked by consistent growth and development in Western Europe and East Asian countries-this earlier period lasted until the middle of 1970s and become known as The Golden Age of Capitalism [15]. From a macroeconomic perspective, the impact of the conflicts on US fiscal aggregates-especially in the case of the Vietnam War-was also an important aspect of the period. In the four decades from the 1940s onwards, inflation, GDP growth, exchange rates, commodity prices, and interest rates experienced accentuated swings, particularly in the US, and these developments ultimately contributed to the dismembering of the international financial agreement designed to guarantee stable exchange rates (Bretton Woods system). Up to the beginning of 1970s, exchange rates stability had been maintained through government interventions in foreign exchange markets-and the levels of international reserves (dollars) in most countries adjusted accordingly.

Since the second half of 1960s, the Vietnam War contributed to reduce-to a certain extent-fiscal stability in the US and to expand the disequilibrium in the balance of payments' current account. A decade earlier foreigners started to accumulate dollar balances in accounts in American banks and, in 1965, the French government began to convert dollars into gold. As the deficit in the US current account increased, the run against the dollar accelerated. In August 1971, Nixon closed the so-called "gold window", refusing to convert dollars into gold, and additionally imposed a $10 \%$ tax on all imports. According to an account of this period, "[the] dollar remained under pressure in the next years until finally the notion of a dollar tied to the price of gold [...] was abandoned altogether" ([16], p. 27).

After the Arab-Israeli war of 1973, the Organization of Petroleum Exporting Countries (OPEC) was successful in imposing severe export quotas on its members, and oil prices increased by a multiple of four. The resulting foreign trade deficits in oil-importing countries, especially in Latin America, created huge profit opportunities for international banks. They provided loans to these countries based on flexible interest rates and secured large premiums [17]. In the beginning of 1980s, the financial scheme that led to transfers of excess funds in international banks to countries with major trade deficits collapsed after the steep interest rate increase promoted by the Fed, and the debt crisis that would have lasting consequences in many developing countries initiated.

As Figure 3 illustrates, despite the conflicts and economic adjustments, the 


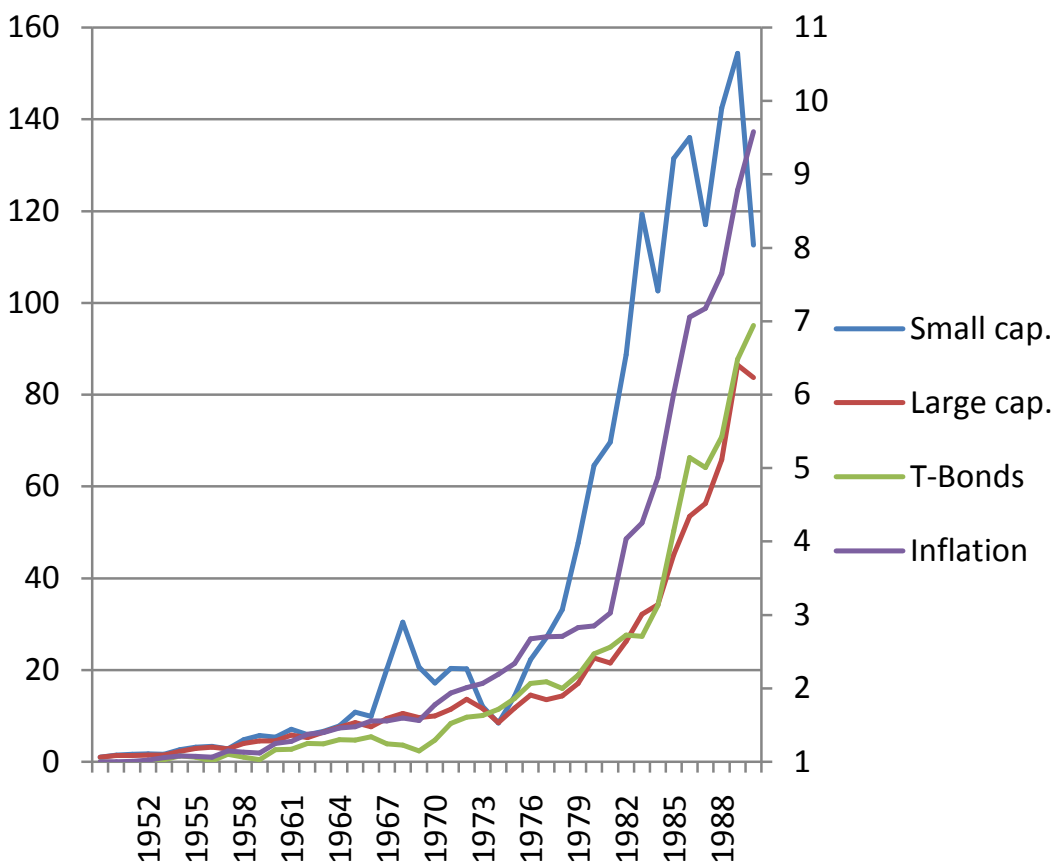

Figure 3. Financial Indicators in the US, 1950-90. Left axis-Russell 2000 stock-market index; Standard \& Poor's 500 stock-market index. Right axis-Yields of Treasury bonds with at least 20 year maturity; CPI annual rates. Note: The starting value of all series is one. Source: [18].

stock market thrived after the Golden Age period, especially in the case of companies with lower market capitalization-the Figure illustrates the high and increasing gains of the Russell index, although in a very volatile fashion, in most of the 1980s. Moreover inflationary pressures, as a rule, were quite strong, and interest rates, as reflected in the yields of Treasury Bonds, accompanied the inflationary surge.

\section{Estimation and Solution of the Macro-Econometric Model}

In this Section, the basic analytical methods that were used in the estimation and solution of the macro-econometric model are presented. Additional details are available in Appendix 1.

\subsection{Data Set and Estimation of the Parameters-Econometric Methods for Structural Equations}

Usually one of the difficult tasks in the development of a macro-econometric model is to assemble the data base for its variables. In the case of the model developed in this paper, the series used were drawn from data available on two traditional textbooks ${ }^{6}$. These series appear in Appendix 2. Table 1 contains the basic statistics for the dependent variables.

The estimation method used here is the Two-Stage Least Squares (2SLS) ${ }^{6}$ The references are [19] and [9]. In the first reference, there are data for $Y, C, I, G$, (EX-IM), nominal $r, w$ and $P$. In the second, there are data for $\left(Y_{-T}\right)$ and $M / P$. 
Table 1. Descriptive statistics—dependent variables. Annual data, 1953-84.

\begin{tabular}{ccc}
\hline & Mean & Std. dev. \\
$\mathrm{Y}^{1}$ & 1065,1 & 320,4 \\
$\mathrm{C}^{1}$ & 660,0 & 214,7 \\
$\mathrm{I}^{1}$ & 161,4 & 54,0 \\
$\mathrm{r}^{2}$ & 2,51 & 2,09 \\
$\mathrm{w} / \mathrm{P}^{3}$ & 89,5 & 9,6 \\
\hline
\end{tabular}

${ }^{1} \$$ billions of 1972 (constant values). ${ }^{2} \% ;{ }^{3}$ Index, $1977=100$.

estimator, which is the most widely used estimator in simultaneous equations models [20]. In this econometric model, it is assumed that the errors follow a multivariate normal distribution. The 2SLS estimator is a particular case of the more general method known as Instrumental Variables (IV) estimator-which, in turn, can be considered an especial case of the Method of Moments applied to regression analysis [21]. It can be shown that estimators obtained from these methods have desirable asymptotical properties-further, under certain conditions, they are asymptotically efficient.

The parameters were estimated using data series for the 1953-79 period (see Appendix 2)-the last five data available in each series were not used. The reason is that this part of the data was reserved so that it could be used to evaluate the model as a prediction tool, that is, beyond the period used in the estimation process. The estimates appear in the two initial columns of Table 2 (2SLS estimator).

\subsection{A Robustness Check of the Model}

Following the approach in [20], it is important to evaluate if the model's equations are correctly specified. The development suggested in that pioneering contribution is to compare estimates based on the 2SLS estimator with a full-information estimator $(3 S L S)^{7}$. To advance on this path, the macro-econometric equations of Section 2.1 were also estimated using Three-Stage Least Squares. The coefficients and standard errors are shown in the final two columns of Table 2. As can be seen, with the exception of the equation for the real interest rate $(r)$, the comparison indicates that the model is correctly specified.

The problem observed with the equation for $r$ was certainly expected given that the behavior of this variable is strongly affected by policy decisions by the Central Bank-in the US, the Fed. This problem is also illustrated in Table 1, which shows that the standard deviation of $r$ is proportionally much bigger than in the case of other endogenous variables. Nevertheless, given that the 2SLS method provides estimates with correct first-derivative signs and, more importantly, to be truthful to the Keynesian inspiration, the macro-econometric model was maintained in its original form.

" 2 SLS is not as efficient as 3SLS, but only the incorrectly specified equation is inconsistently estimated if misspecification is present in the system." ([20], p. 1265). 
Table 2. Parameter estimates. Data series: 1953-79.

\begin{tabular}{cccccc}
\hline & & \multicolumn{2}{c}{ 2SLS estimator } & \multicolumn{2}{c}{ 3SLS estimator } \\
\hline C & Regres. & Coef. & St. error & Coef. & St. error \\
& 1 & 8.052 & 5.297 & 8.910 & 5.484 \\
& $\mathrm{Y}-\mathrm{T}$ & 0.8947 & 0.0076 & 0.8934 & 0.0079 \\
\hline $\mathrm{I}$ & 1 & -6.437 & 12.591 & -5.876 & 11.527 \\
& $\mathrm{r}$ & -3.394 & 4.2453 & -3.443 & 3.7754 \\
& $\Delta \mathrm{Y}$ & 0.5975 & 0.1182 & 0.7136 & 0.1051 \\
& $\mathrm{Y}-1$ & 0.1503 & 0.0095 & 0.1459 & 0.0089 \\
& 1 & 1.162 & 0.9955 & 2.474 & 1.448 \\
& $\mathrm{M} / \mathrm{P}$ & -0.0173 & 0.00978 & 0.0051 & 0.0108 \\
& $\mathrm{Y}$ & 0.00423 & 0.00277 & -0.0017 & 0.0033 \\
\hline $\ln (\mathrm{w} / \mathrm{P})$ & 1 & 1.832 & 0.1551 & 1.823 & 0.2323 \\
& $\ln \mathrm{Y}$ & 0.3870 & 0.0226 & 0.3883 & 0.0338 \\
\hline
\end{tabular}

Source: Estimates obtained by the author.

\subsection{Solving a System of Nonlinear Equations-Each Simulation Period Contains a Problem to Be Solved}

Solution methods of nonlinear systems of equations are based upon-with a decreasing level of generality-fixed-point theorems, the method of successive approximations, and the so-called Newton (or Newton-Raphson) method [22] and [23].

The modified Newton method (Appendix 1) is quite easily translated into computer code-in the case of the model solved here, a spreadsheet was used to provide the solutions. This arrangement is very convenient, since the construction of data series for the variables, the estimation of the equations' parameters, and the model's dynamic solution can all be performed in different spreadsheets of the same file.

The first period for which the model was solved was 1954, using data for the previous year-which also provided a starting solution for the successive approximations method. After that, the solution obtained in one period was used as a starting point for the following year. In each period, the modified Newton method was utilized and, as a rule, only a few iterations were necessary to achieve convergence. Therefore, in terms of data for the endogenous variables, only information for 1953 was, in fact, used. In other words, the values for the endogenous variables obtained from the model reflect only the dynamic properties of the nonlinear system, and the trend of the exogenous variables-which are quite limited in number (only five).

\section{Analysis of the Model's Solutions: Macroeconomic Trends in the American Economy from the 1950s to 1980s}

The solutions obtained from the five-equation macro-econometric model, together with the historical series, are displayed in Figure 4. The most significant 

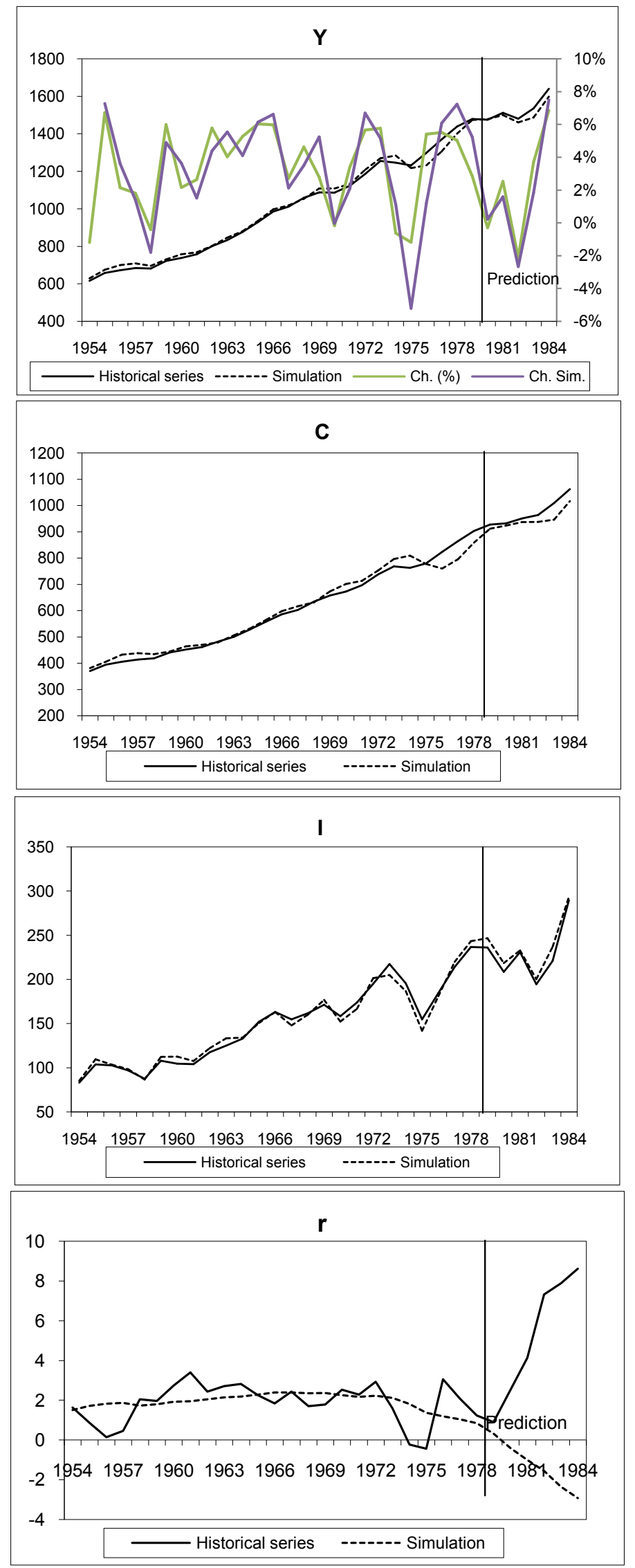


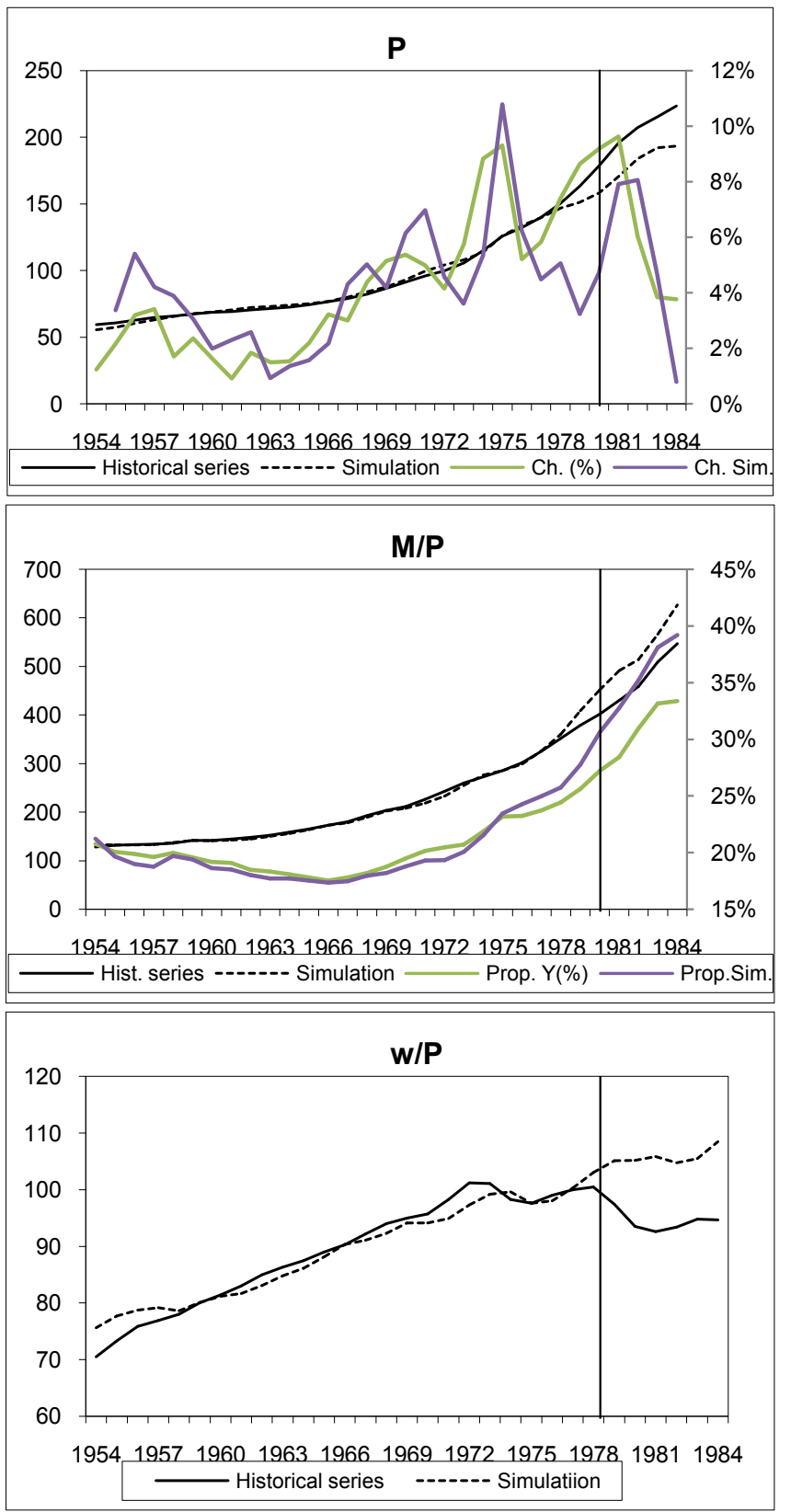

Figure 4. Model's solutions and historical series. Notes: 1) For the units used in each graph, see Appendix 2. 2) The prediction period contains "out of sample" data-i.e., data that were not used in parameter estimation.

graph is probably the one for aggregate investment $(I)$-the true dynamic variable in the model. Based on this graph, one can conclude that the model captured fairly well the dynamic pattern of the real economy $y^{8}$. On the other hand, one should not over emphasize this aspect of the model's solutions-that they were quite close to historical values-, given the especial nature of the exogenous variables. Although these variables are limited in number, each one represents fundamental and complex parts of the macroeconomic system. For example, the ${ }^{8}$ Putting it differently, the econometric "artist" was successful. 
solutions for the endogenous variables depend on the paths of the nominal wage rate $(w)$ and the trade balance $(E X-I M)$.

In the case of empirical analyses, the most valuable feature of a structural macro-econometric model is that it reveals, among hundreds of different types of information available to researchers, what we should be concentrating on. More explicitly, if the model reproduces reasonably well the pattern of real macroeconomic variables, and given that the model's solutions derive from the exogenous variables and the model's dynamic properties, then it is a logical conclusion that these exogenous variables are the really important ones-and there are only five of them to take into consideration'.

In other words, one of the main accomplishments of this macro-econometric model is that it reveals that researchers and analysts in general should pay especial attention to the trends of average nominal wage, trade balance, government spending, taxes, and money supply. Further, the model produces sophisticatedly simple solutions from the paths of these variables, either historical or projected-solutions that can be of value in understanding both historical and future macroeconomic policies and trends.

\section{Historical Trends of the Exogenous Variables: Exploring the Relation with the Macroeconomic Developments in the US}

The examination of the historical path of the model's exogenous variables (Figure 5) reveals that there were, roughly, fiscal surpluses in the whole period from 1954 to $1984^{10}$. In several years, the growth of government revenues surpassed that of spending, but in the second half of 1970s, the opposite relation was also present. On the other hand, the average hourly wage in real terms remained relatively stagnant from 1954 to $1984-$ for example, real government spending and revenues rose $193.7 \%$ and $221.6 \%$, respectively, in the period examined whereas the growth rate for the real wage was only $143.4 \%$. This moderate performance certainly contributed to contain inflationary pressures in a period marked by very strong increases in money supply-the growth rate of money balances in real terms was $469.5 \%$. Nevertheless, the most irregular behavior among the exogenous variables belongs to trade balance, which started at a level close to zero in 1954 (billions of 1972 dollars), reached a maximum of $\$ 50.3$ billion in 1980, and plummeted to a deficit of \$14.2 billion in 1984 .

Next, an overall evaluation of the macroeconomic trends observed in the US from 1954 to 1984, coupled with the factors that most likely explain this behavior, is put forward:

1) Growth rates of GNP and aggregate investment were relatively high in those years-the geometric averages are, respectively, $3.2 \%$ and $4.2 \%{ }^{11}$. The main ${ }^{9}$ A mathematical analysis of the dynamic behavior of a structural model with lagged endogenous variables, and the factors behind it, is available in [9].

${ }^{10}$ Rigorously the data used for $T$ cannot be contrasted to $G$ in order to obtain the fiscal surplus due to the fact that social security contributions are included in $T$. The difference, though, amounts roughly to $10 \%$ of the total, which does not invalidate the conclusions drawn here.

${ }^{11}$ Total private investment is used for $I$. 


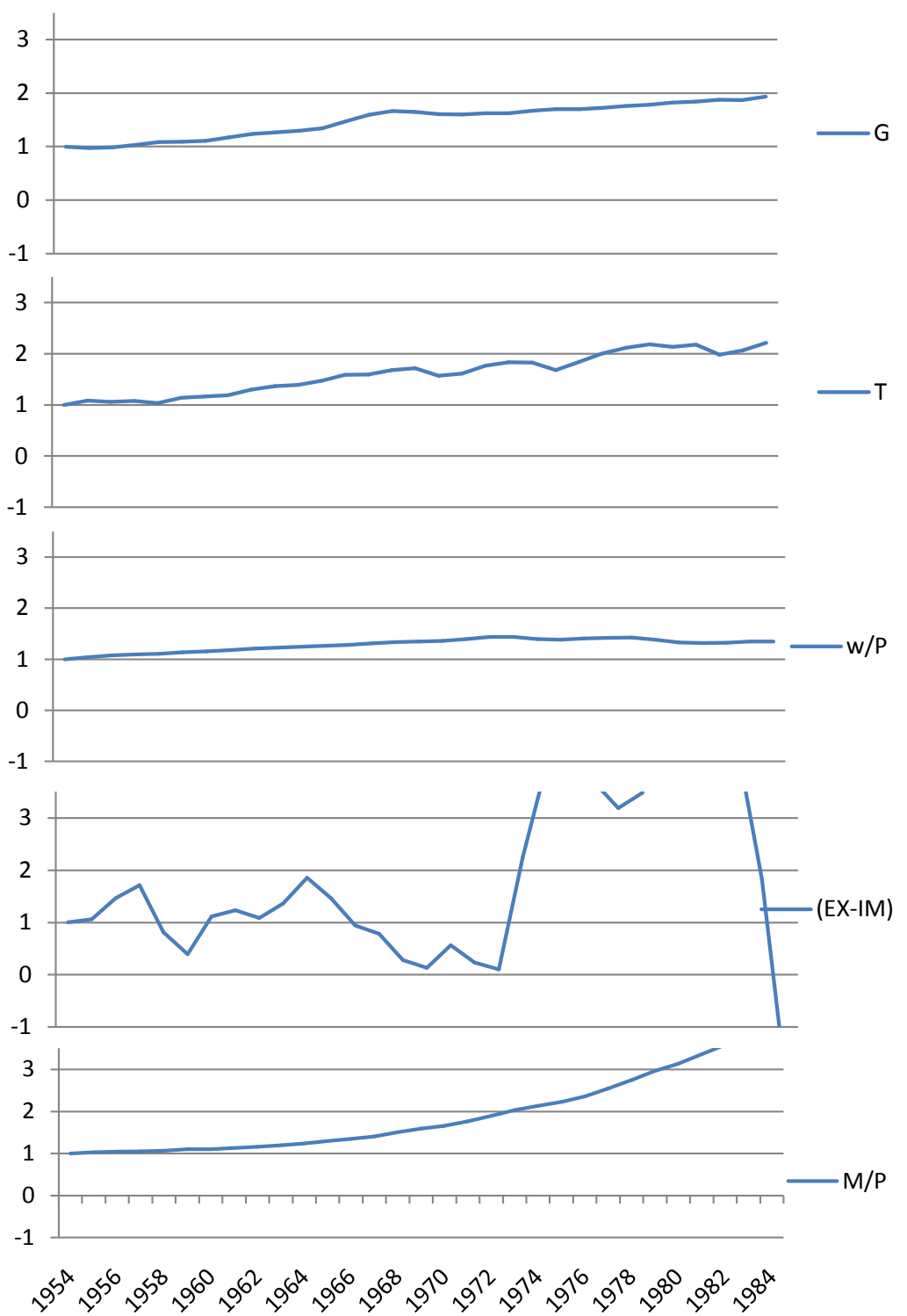

Figure 5. Model's exogenous variables, 1954-84. G: government spending; T: taxes; w/P: average wage rate; EX-IM: trade balance; M/P: money stock in real terms. Notes: In the first year (1954) all values are set to one. All variables are in real values. For the units used, see Appendix 2. Source: See Appendix 2.

factors behind this trend is a consistent growth of government consumption (average of 2.2\%) and, more importantly, of money supply in real terms (5.0\%).

2) The considerable fall of GNP in $1975(-5.2 \%)$ was due mainly to the strong upsurge of inflation, due to the oil crisis-a trend that was duly captured by the model's solutions. The slow growth of the average wage in the period examined -in particular, after the first oil crisis-contributed to reduce inflationary pressures and to sustain GDP growth-very much in line with Keynes' analysis. In real terms, the overall average growth rate of wages was only $1.2 \%$.

3) The fall of GNP in $1982(-2.3 \%)$ was due to the rise of inflation caused by the second oil crisis and, especially, by the strong increase of real interest rates 
imposed by the Fed-nevertheless, the changes observed in real interest rates in this period were not adequately reflected in the model's solutions.

4) The trade balance was a clear factor contributing to higher GNP growth from 1972 to 1981, but it had the opposite effect afterwards. The available evidence suggests that the contribution of the trade balance to GNP growth was especially important, given that, after 1981, there was a significant reduction of economic growth.

\section{Concluding Remarks}

The analyses in the previous Sections indicate that simple structural macro-econometric models-even very small ones, as the model examined herecan be valuable tools in the effort to understand and explain main macroeconomic tendencies and variables, as well as in exercises aimed at forecasting future developments. In this way, they contain relevant information for macroeconomic researchers and analysts. On the other hand, it is important to emphasize that, as one would expect, there is no "magic bullet" here. Even though sophisticatedly simple macro-dynamic models can combine information in a systematic way, and generate solutions that would not be available otherwise, these solutions derive from exogenous variables that depend themselves on involved economic relations.

One drawback of structural macro-econometric models is that, before they can be applied to problems in the economic field and in financial markets, a number of previous tasks must be successfully completed, in particular: development of relevant macro-econometric equations, building of data bases for the model's variables, estimation of the parameters using adequate econometric methods, and the application of mathematical methods for the solution of nonlinear systems of equations-in this last case, there is also the need to write adequate computer code. In relation to these points, one favorable aspect is that sophisticated software tools are currently available to deal with all these tasks.

In the period that was examined, the macro-econometric model based on Keynes' analytical system was very successful in reproducing the endogenous variables' dynamic patterns, with the significant exception of the real exchange rate $(r)$. The main conclusion is that there is convincing evidence that a simple structural dynamic macro-econometric model, as the one developed here, can be of help in assessing historical macroeconomic policies and tendencies-as well as in evaluating likely future trends.

One aspect that it is worth to elaborate on is the especial role of the exogenous variables in a model. In the areas of Macroeconomics and Finance, there are hundreds of different variables and data series that researchers and professionals may regard as relevant information. Nevertheless, if a structural simple model is employed, and if we can conclude that it reproduces reasonably well the dynamic patterns of macroeconomic variables in a certain period, and considering further that the model's solutions derive from the exogenous variables in connection 
with the model's dynamic properties, then it is fair to conclude that the models' exogenous variables can explain the macroeconomic patterns of that periodand in the case of the model examine here, there are only five of these variables to take into account.

Therefore one of the main accomplishments of this analysis is that, in the period examined, it reveals that one should pay special attention to the trends of the average nominal wage, trade balance, government spending, taxes, and money supply. Moreover, given the historical trends of these variables, the model produced solutions for the paths of the endogenous variables-GNP, aggregate consumption, private investment, and average price level-that were very close to the historical series and, moreover, captured the actual changes and cycles.

\section{References}

[1] Klein, L.R. (1950) Economic Fluctuations in the United States: 1921-1940. John Wiley, New York.

[2] Kalecki, M. (1954) Theory of Economic Dynamics: An Essay on Cyclical and Long-Run Changes in Capitalist Economy. George Allen and Unwin, London.

[3] Allen, R.G.D. (1968) Macro-Economic Theory: A Mathematical Treatment. Macmillan, London.

[4] DeVroey, M. and Malgrange, P. (2009) From the Keynesian Revolution to the Klein-Goldberger Model. Working Paper, Siena University, Italy.

[5] Klein, L.R. and Goldberger, A.S. (1955) An Econometric Model for the United States, 1929-1952. North-Holland, Amsterdam.

[6] Christ, C.F. (1966) Econometric Models and Methods. Wiley, New York.

[7] Desai, M. (1977) Applied Econometrics. Philip Allan, Oxford.

[8] Pindyck, R.S. and Rubinfeld, D.L. (1981) Econometric Models and Economic Forecasts. 2nd Edition, McGraw-Hill, Singapore.

[9] Greene, W.H. (1997) Econometric Analysis. 3rd Edition, Prentice Hall, Upper Saddle River.

[10] Heesterman, A.R.G. (1970) Forecasting Models for National Economic Planning. Gordon and Breach, New York. https://doi.org/10.1007/978-94-017-6214-4

[11] Wallis, K.F. and Whitley, J.D. (1991) Macro Models and Macro Policy in the 1980s. Oxford Review of Economic Policy, 7, 118-127. https://doi.org/10.1093/oxrep/7.3.118

[12] Bodkin, R.G., Klein, L.R. and Marwah, K. (1991) A History of Macro-Econometric Model-Building. Edward Elgar, Aldershot.

[13] da Fonseca, M.A.R. (2005) Exploring the Role of Macro-Models in Economic Development and Portfolio Analysis: An Empirical Study. Seminar Series, REALRegional Economics Applications Laboratory, University of Illinois, Urbana-Champaign.

[14] Da Fonseca, M.A.R. (2006) Planejamento e Desenvolvimento Econômico. Thomson-Cengage, São Paulo.

[15] Marglin, S.A. (1988) Lessons of the Golden Age of Capitalism. World Institute for Development, United Nations University, New York. 
[16] Kindleberger, C.P. (1995) The World Economy and National Finance in Historical Perspective. The Univ. of Michigan Press, Ann Arbor.

[17] Bulmer-Thomas, V. (2003) The Economic History of Latin America since Independence. 2nd Edition, Cambridge University Press, Cambridge.

[18] Bodie, Z., Kane, A. and Marcus, A. (2009) Investments. 8th Edition, McGraw-Hill, New York.

[19] Baumol, W.J. and Blinder, A.S. (1985) Economics-Principles and Policy. 3rd Edition, Harcourt-Brace-Jovanovich, New York.

[20] Hausman, J.A. (1978) Specification Tests in Econometrics. Econometrica, 46, 1251-1271. https://doi.org/10.2307/1913827

[21] Campbell, J.Y., Lo, A.W. and Mackinlay, A.C. (1997) The Econometrics of Financial Markets. Princeton University Press, Princeton.

[22] Franklin, J. (1980) Methods of Mathematical Economics. Springer-Verlag, New York.

[23] Strang, G. (1986) Introduction to Applied Mathematics. Wellesley-Cambridge Press, Wellesley, MA

[24] Maddala, G.S. (1977) Econometrics. McGraw-Hill, Singapore. 


\section{Appendix 1}

\subsection{Model Estimation}

The basic formula for the 2SLS estimator, applied to the $i$-th equation $\left(\bar{\delta}_{i}\right)$, is:

$$
\bar{\delta}_{i}=\left(\bar{Z}_{i}^{T} \bar{Z}_{i}\right)^{-1} \bar{Z}_{i}^{T} y_{i}
$$

In Equation (8), the data for the corresponding endogenous variable are included in $y_{i}$. Matrix $\bar{Z}_{i}$ is defined as:

$$
\bar{Z}_{i}=\left[\bar{Y}_{i} \mid X_{i}\right]
$$

In this matrix, $X_{i}$ contains the data for the exogenous (and lagged endogenous) variables included in the $i$-th equation, and the $\bar{Y}_{i}$ part contains the instruments - forecasts for the endogenous variables in the $i$-th equation, which are generated using the model in its reduced form [24]. All the estimation procedures for the model's equations were developed in a spreadsheet file. Further, the full-information 3SLS estimator is a natural, although cumbersome, alternative in which residuals derived from 2SLS are used to estimate the covariance matrix of the errors-this matrix is then included in the estimation procedure [24].

\subsection{Model Solution}

Fixed-point theorems establish that, under certain conditions, the solution of the equation $x=f(x)$ exists. One important aspect of this analysis is that any equation can be put in the form of the fixed-point equation. For example, if the original equation is $g(x)=0$, then one corresponding $x=f(x)$ equation is:

$$
x=x+g(x)
$$

The method of successive approximations is, at the same time, one way to prove the theorem and a method to find the solution. In this iterative scheme, one computes the successive approximations: ${ }^{12}$

$$
x_{n+1}=f\left(x_{n}\right) ; n=0,1,2,
$$

The method associated to Newton is an important example of the iterations in (11). Representing the $i$-th equation in a nonlinear system by $g_{i}(x)=0$, where the symbol $x$ represents the set (vector) of endogenous variables, the method provides the solution in each stage-or approximation- $\left(x_{k+1}\right)$ from the previous one $\left(x_{k}\right)$ through the following linear system:

$$
x_{k+1}=x_{k}-\left(J_{k}\right)^{-1} g_{k}
$$

In Equation (12), $J_{k}$ represents the Jacobian matrix (of first derivatives) obtained in stage $k$, and $g_{k}$ is a vector with the results calculated at the same stage for the functions $g_{i}$. Usually, the Newton method converges quickly for the correct solution. One difficulty with this method is that the Jacobian matrix must be calculated at each step and, naturally, in a more convenient version of the me-

${ }^{12}$ To prove the fixed-point theorem, it is sufficient to establish the convergence of the sequence $x_{n}$. 
thod-albeit one in which convergence to the solution is not so quick, neither so much guaranteed-this matrix is fixed. In the so-called modified Newton method, only the Jacobian matrix for the first stage (0) is used:

$$
x_{k+1}=x_{k}-\left(J_{0}\right)^{-1} g_{k}
$$

\section{Appendix 2}

Data for major macroeconomic variables: USA, 1953-84 ${ }^{1}$

\begin{tabular}{|c|c|c|c|c|c|c|c|c|c|c|}
\hline & $Y$ & $C$ & $I$ & $G$ & $(E X-I M)$ & $(Y-T)$ & $r_{\text {nom }}^{2}$ & $P^{3}$ & $M / P^{4}$ & $w^{5}$ \\
\hline 1953 & 623.6 & 363.4 & 85.3 & 170.1 & 4.8 & 399.1 & 1.62 & 58.82 & 126 & 39.93 \\
\hline 1954 & 616.1 & 370 & 83.1 & 156 & 6.9 & 403.6 & 1.64 & 59.55 & 128 & 41.48 \\
\hline 1955 & 657.5 & 394.1 & 103.8 & 152.3 & 7.3 & 427 & 0.87 & 60.84 & 132 & 44.07 \\
\hline 1956 & 671.6 & 405.4 & 102.6 & 153.5 & 10.1 & 446.5 & 0.15 & 62.79 & 133.5 & 47.09 \\
\hline 1957 & 683.8 & 413.8 & 97 & 161.2 & 11.8 & 455.2 & 0.47 & 64.93 & 134.1 & 49.34 \\
\hline 1958 & 680.9 & 418 & 87.5 & 169.8 & 5.6 & 461 & 2.05 & 66.04 & 136 & 50.9 \\
\hline 1959 & 721.7 & 440.4 & 108 & 170.6 & 2.7 & 479.3 & 1.97 & 67.6 & 141.4 & 53.44 \\
\hline 1960 & 737.2 & 452 & 104.7 & 172.8 & 7.7 & 489.6 & 2.74 & 68.7 & 141.4 & 55.26 \\
\hline 1961 & 756.6 & 461.4 & 103.9 & 182.9 & 8.5 & 503.9 & 3.4 & 69.33 & 144.5 & 56.86 \\
\hline 1962 & 800.3 & 482 & 117.6 & 193.2 & 7.5 & 524.8 & 2.44 & 70.61 & 148 & 59.31 \\
\hline 1963 & 832.5 & 500.5 & 125.1 & 197.6 & 9.4 & 542.7 & 2.72 & 71.67 & 152.6 & 61.12 \\
\hline 1964 & 876.4 & 528 & 133 & 202.6 & 12.8 & 580.5 & 2.82 & 72.77 & 158.6 & 62.92 \\
\hline 1965 & 929.3 & 557.5 & 151.9 & 209.8 & 10.1 & 616.3 & 2.26 & 74.36 & 165.5 & 65.4 \\
\hline 1966 & 984.8 & 585.7 & 163 & 229.7 & 6.5 & 647 & 1.84 & 76.76 & 172.8 & 68.49 \\
\hline 1967 & 1011.4 & 602.7 & 154.9 & 248.5 & 5.4 & 673.1 & 2.44 & 79.06 & 180 & 72.03 \\
\hline 1968 & 1058.1 & 634.4 & 161.6 & 260.2 & 1.9 & 701.4 & 1.7 & 82.54 & 192.7 & 76.67 \\
\hline 1969 & 1087.6 & 657.9 & 171.4 & 257.4 & 0.9 & 722.7 & 1.79 & 86.79 & 203.8 & 81.47 \\
\hline 1970 & 1085.6 & 672.1 & 158.5 & 251.1 & 3.9 & 751.7 & 2.53 & 91.45 & 211.6 & 86.48 \\
\hline 1971 & 1122.4 & 696.8 & 173.9 & 250.1 & 1.6 & 779.1 & 2.29 & 96.01 & 226.2 & 93.26 \\
\hline 1972 & 1185.9 & 737.1 & 195 & 253.1 & 0.7 & 810.3 & 2.93 & 100 & 242.6 & 100 \\
\hline 1973 & 1254.3 & 767.9 & 217.5 & 253.3 & 15.5 & 865.2 & 1.6 & 105.75 & 259.7 & 105.65 \\
\hline 1974 & 1246.3 & 762.8 & 195.5 & 260.3 & 27.8 & 857.7 & -0.23 & 115.08 & 272.6 & 111.78 \\
\hline 1975 & 1231.6 & 779.4 & 154.8 & 265.2 & 32.2 & 874.8 & -0.44 & 125.79 & 285.4 & 121.32 \\
\hline 1976 & 1298.2 & 823.1 & 184.5 & 265.2 & 25.4 & 906.9 & 3.06 & 132.34 & 301.9 & 129.46 \\
\hline 1977 & 1369.7 & 864.3 & 214.2 & 269.2 & 22 & 943.3 & 2.07 & 140.05 & 325.2 & 138.39 \\
\hline 1978 & 1438.6 & 903.2 & 236.7 & 274.6 & 24 & 988.6 & 1.23 & 150.42 & 351.7 & 149.38 \\
\hline 1979 & 1479.4 & 927.6 & 236.3 & 278.3 & 37.2 & 1015.5 & 0.91 & 163.42 & 379 & 157.28 \\
\hline 1980 & 1475 & 931.8 & 208.5 & 284.3 & 50.3 & 1021.7 & 2.53 & 178.42 & 401.5 & 164.84 \\
\hline 1981 & 1512.2 & 950.5 & 230.8 & 287 & 43.8 & 1049.7 & 4.14 & 195.6 & 430.1 & 178.98 \\
\hline 1982 & 1480 & 963.3 & 194.4 & 292.7 & 29.7 & 1058.5 & 7.33 & 207.38 & 458.5 & 191.4 \\
\hline 1983 & 1534.7 & 1009.2 & 221.1 & 291.9 & 12.6 & 1095.5 & 7.9 & 215.34 & 509.2 & 201.72 \\
\hline 1984 & 1639.9 & 1062.4 & 289.6 & 302.1 & -14.2 & 1169.1 & 8.62 & 223.44 & 547.3 & 209.09 \\
\hline
\end{tabular}

1. Variables in billions of 1972 dollars, $r_{n o m}$ in $\%, P$ and $w$ are indices $(1972=100) .2$. Average interest rates on bonds issued by top level companies. 3. GNP deflator. 4. $\mathrm{M}_{1}$ stock. 5. Average hourly nominal wage. Sources: [9] and [19]. 